Boise State University

ScholarWorks

Psychological Sciences Faculty Publications and

Presentations

Department of Psychological Science

4-1-2017

Western Diet Affects the Murine Circadian System
Possibly Through the Gastrointestinal Microbiota

Roberto Refinetti

Boise State University 
This is an author-produced, peer-reviewed version of this article. The final, definitive version of this document can be found online at Biological Rhythm Research, published by Taylor \& Francis. Copyright restrictions may apply. doi: 10.1080/09291016.2016.1254873

\title{
Western Diet Affects the Murine Circadian System Possibly Through the Gastrointestinal Microbiota
}

\author{
Roberto Refinetti \\ Circadian Rhythm Laboratory \\ Department of Psychological Science \\ Boise State University \\ Boise, ID \\ refinetti@circadian.org
}

\begin{abstract}
Consumption of a high-fat diet characteristic of human Western diet has been shown to affect the circadian system of laboratory rodents. The present study confirms an effect of Western diet on the circadian system of mice, specifically a shortening of the free-running circadian period of running-wheel activity, in addition to increased weight gain. Decimation of the gut microbiota by broad spectrum antibiotic treatment reversed the effect of Western-diet feeding on the free-running period, which suggests that the effect of Western-diet feeding on the circadian system is mediated by the gastrointestinal microbiota. This finding is particularly relevant in view of recent studies describing a relationship between gut microbes, circadian clock function, and obesity.
\end{abstract}

Keywords: circadian, gastrointestinal flora, high-fat diet, locomotor activity, Mus musculus, obesity

\section{Introduction}

The metabolic syndrome, a disorder generally characterized by obesity, insulin resistance, hyperglycemia, hyperlipidemia, and increased risk of cardiovascular disease, affects a large segment of the human population in developed nations (Spalding et al. 2009; Cameron 2010; Gade et al. 2010). Although many etiological factors likely contribute to the syndrome, overeating and selection of inadequate diets are considered to be major contributors (Abete et al. 2010). In particular, the Western diet (a diet common in developed nations in the Western hemisphere, which is characterized by excessive consumption of a reduced variety of refined sugars, salt, and saturated fat) is likely a contributor to the metabolic syndrome and other chronic diseases (Cordain et al. 2005; Jaworowska et al. 2013; Myles 2014).

Recent research has documented a close connection between energy metabolism and the operation of the circadian clock at the cellular level (Nakahata et al. 2009; Ramsey et al. 2009; Peek et al. 2013), and it is sensible to inquire whether consumption of the Western diet might affect the operation of the circadian clock. A few studies have directly or indirectly addressed this question. Mendoza and colleagues found that a high-fat diet can reduce the sensitivity of the circadian system to the phase-shifting action of light (Mendoza et al. 2008), and Hsieh and colleagues documented a change in the expression of various circadian-clock genes in livers and kidneys of mice fed a high-fat diet (Hsieh et al. 2010). Notably, Kohsaka and colleagues found that high-fat feeding not only affected the expression of circadian-clock genes but also had a measurable effect on organismal function in the form of a small lengthening of the free-running period of the locomotor activity rhythm (Kohsaka et al. 2007). This latter finding is important because the free-running period of the activity rhythm is a reflection of the speed of the circadian clock, which is a fundamental property of the circadian system that distinguishes circadian rhythms from biological oscillations in the ultradian and infradian ranges.

The present study was conducted to further evaluate the reported effect of diet on the free-running period of the activity rhythm in mice. Because changes in diet are known to affect the gastrointestinal microbiota (Albenberg \& Wu 2014; Conlon \& Bird 2014), and because changes in the gastrointestinal microbiota have been associated with the weight gain that results from consumption of high-fat diets (Vijay-Kumar et al. 2010; Ridaura et al. 2013), this 
This is an author-produced, peer-reviewed version of this article. The final, definitive version of this document can be found online at Biological Rhythm Research, published by Taylor \& Francis. Copyright restrictions may apply. doi: 10.1080/09291016.2016.1254873

study included a condition in which mice had their gut microbiota decimated by antibiotic treatment. This allowed a direct test of the hypothesis that decimation of the gut microbiota can reverse the effect of Western-diet feeding on the free-running circadian period.

\section{Materials and Methods}

\subsection{Animals}

Two-month-old male mice (Mus musculus) of the CD-1 strain were purchased from Charles River Laboratories (Wilmington, MA) and were housed individually in polypropylene cages (24 x 36 x $19 \mathrm{~cm})$ lined with wood shavings and fed Purina rodent chow (Rodent Diet 5001, Lab Diet, St. Louis, MO) and water ad libitum. The animal cages were maintained in individual light-tight, ventilated chambers at $24 \pm 2{ }^{\circ} \mathrm{C}$ under a 12L:12D light-dark cycle.

\subsection{Equipment}

The rhythm of running-wheel activity was used as a measure of the state of the circadian pacemaker. A metallic running wheel (12 cm diameter) was attached to each animal cage. Magnetic switches attached to the running wheels were connected to data acquisition boards (Digital Input Card AR-B2001, Acrosser Technology, Taiwan). The data acquisition boards were connected to computers that recorded the number of wheel revolutions in 6-min bins (i.e., $0.1 \mathrm{~h}$ intervals). To reduce animal disturbance, cages and water bottles were replaced at monthly intervals, under dim red light if necessary.

Food consumption was computed as the difference in the weight of food at the beginning and end of a monitoring interval. Food was weighed with $0.1 \mathrm{~g}$ resolution in an Ohaus Scout Pro balance (Ohaus Corp., Pine Brook, NJ). Energy content of the food was determined according to the manufacturer's specifications, as described below. Body mass of individual mice was determined with $0.1 \mathrm{~g}$ resolution in the same Ohaus balance used to weigh the food.

\subsection{Procedure}

Two groups of 30 mice were used in two separate experiments. In Experiment 1, 30 individually-housed mice were kept under a 12L:12D light-dark cycle and were fed regular rodent chow (Lab Diet 5001) for four weeks before being released into constant darkness. After three weeks in constant darkness, half of the animals were switched to a Western diet and the other half to a control diet. Data collection continued for seven more weeks.

Western diet (Diet 5TJN) and control diet (Diet 5TJS) were purchased as rodent pellets from Purina Animal Nutrition (Test Diet, St. Louis, MO). Bomb calorimetry data provided by the manufacturer indicate that the physiological fuel value of the Western diet is $18.8 \mathrm{~kJ} / \mathrm{g}$ partitioned as $16 \%$ protein, $40 \%$ fat, and $44 \%$ carbohydrates. The physiological fuel value of the control diet is $15.2 \mathrm{~kJ} / \mathrm{g}$ partitioned as $16 \%$ protein, $12 \%$ fat, and $72 \%$ carbohydrates. The control diet matches the protein content of the Western diet, which is less than that of the regular rodent chow (29\% protein, $13 \%$ fat, and $58 \%$ carbohydrates).

In Experiment 2, 30 individually-housed mice were kept under a 12L:12D light-dark cycle and were fed regular rodent chow (Lab Diet 5001) for four weeks before being subdivided into three groups: two groups were fed the Western diet for the next 8 weeks, whereas the third group was fed the control diet. One of the groups switched to the Western diet was subjected to a treatment to decimate the gut flora starting one week before the switch to the Western diet and lasting for the remaining of the study (thus, a total of 9 weeks). The treatment consisted of administration of broad spectrum antibiotics in the drinking water. The antibiotics were ampicillin $(1.0 \mathrm{~g} / \mathrm{L})$ and neomycin $(0.5 \mathrm{~g} / \mathrm{L})$, which are poorly absorbed and affect primarily the intestinal microbiota without general systemic effects (Vijay-Kumar et al. 2010).

\subsection{Data analysis}

The records of running-wheel activity were analyzed for temporal patterns through the chi square periodogram procedure (Sokolove \& Bushell 1978; Refinetti 2004) and were also used as a measure of energy expenditure (number of wheel revolutions per day). There is no exact calibration of running-wheel activity as a measure of energy expenditure, but the two variables are positively correlated (Refinetti and Menaker 1997). Significance tests 
This is an author-produced, peer-reviewed version of this article. The final, definitive version of this document can be found online at Biological Rhythm Research, published by Taylor \& Francis. Copyright restrictions may apply. doi: 10.1080/09291016.2016.1254873

for differences between group means (for circadian period, food intake, body mass, and activity level) were conducted either by $t$ tests or by analysis of variance (ANOVA), as appropriate. Post hoc pairwise comparisons were conducted with Tukey's HSD test (Kirk 1995).

\section{Results}

All mice exhibited robust rhythmicity of running-wheel activity. Records of running-wheel activity of representative mice from the two groups in Experiment 1 are shown in Figure 1. The animal whose records are shown in the left panel (A) was fed the control diet and exhibited the typical free-running rhythm of a mouse, with a circadian period shorter than $24 \mathrm{~h}$ that lengthens gradually over several weeks. The other mouse (B) was fed the Western diet and did not exhibit lengthening of the circadian period. The means for all mice in the two groups are shown in Figure 2. Starting around the third week after the different diets were introduced, the mice that were fed the control diet started to exhibit a longer free-running period than the mice that were fed the Western diet, so that by the end of the experiment the circadian period of the mice fed the control diet was $0.3 \mathrm{~h}(18 \mathrm{~min})$ longer than that of the mice fed the Western diet. A factorial analysis of variance revealed a significant interaction effect (diet vs. weeks): $F(9,252)$ $=2.256, p=0.019$.

The group results for food intake, body mass, and activity level are shown in Figure 3. The amount of food eaten (g/day) did not differ between the two groups $(t(28)=1.188, p=0.245)$, but, because the two diets had different energetic contents, the Western diet group consumed more energy (kJ/day) than the control group $(t(28)=4.498, p<$ 0.001). Whereas the two groups had comparable body masses before the different diets were introduced, the Western diet group was heavier than the control diet group by the end of the experiment, as confirmed by a marginally significant interaction effect (diet vs. weeks): $F(1,28)=4.187, p=0.050$. Although there were group differences in the mean level of activity (expressed as the number of wheel revolutions per minute), the variances were relatively large, and no significant differences between means were identified by a factorial ANOVA: $F(1,28)$ $=0.972, p=0.333$ for the effect of diet; $F(1,28)=2.611, p=0.117$ for the effect of weeks; and $F(1,28)=1.102, p$ $=0.303$ for the interaction effect.

The results from Experiment 2 concerning the free-running period are shown in Figure 4. As had been the case in Experiment 1, the circadian period of the Western diet group remained constant throughout the experiment, whereas the circadian period of the control group gradually lengthened, even if not as markedly as in Experiment 1. Interestingly, antibiotic treatment not only inhibited the effect of the Western diet but seemed to have an additional lengthening effect on the free-running period. One-way ANOVAs identified a significant effect of time (weeks) in the control group $(F(7,63)=2.197, p=0.046)$ and the antibiotic-treated Western diet group $(F(7,63)=3.628, p=$ $0.002)$ but not in the non-treated Western diet group $(F(7,63)=0.692, p=0.678)$. A two-way ANOVA involving the control diet group and the antibiotic-treated group confirmed a statistically significant effect of time $(F(7,126)=$ 4.283, $p<0.001$ ) but not a significant difference between the two groups $(F(1,18)=0.277, p=0.605)$ nor a significant interaction of the two factors $(F(7,126)=0.926, p=0.489)$.

The group results for food intake, body mass, and activity level in Experiment 2 are shown in Figure 5. The amount of food eaten (g/day) did not differ between the groups $(F(2,27)=1.284, p=0.293)$, but, because the diets had different energetic contents, the Western diet groups consumed more energy ( $\mathrm{kJ} /$ day) than the control group $(F(2$, $27)=28.210, p<0.001)$. Although the three groups had comparable body masses before the different diets were introduced, the two Western diet groups were heavier than the control diet group by the end of the experiment, as confirmed by a significant interaction effect (diet vs. weeks): $F(2,27)=3.678, p=0.039$. The Western diet group treated with antibiotics gained less weight than the untreated Western diet group, but the difference was not statistically significant. The activity level (revol/min) measured under a light-dark cycle before the introduction of the different diets was comparable in the three groups. The activity level measured in constant darkness towards the end of the experiment was significantly higher than that measured under the light-dark cycle at the beginning (Effect of time: $F(1,27)=8.197, p=0.008)$, but there were no significant group differences (Effect of group: $F(2,27)=$ $0.235, p=0.792$; Interaction effect: $F(2,27)=1.484, p=0.245)$. 
This is an author-produced, peer-reviewed version of this article. The final, definitive version of this document can be found online at Biological Rhythm Research, published by Taylor \& Francis. Copyright restrictions may apply. doi: 10.1080/09291016.2016.1254873

\section{Discussion}

In two separate experiments, mice fed a Western diet ( $40 \%$ fat) exhibited a shorter circadian period than mice fed a control diet (12\% fat). The difference in circadian period was small (approximately $0.2 \mathrm{~h}$, or $12 \mathrm{~min}$, on average for the two experiments) but statistically significant. Such a difference is physiologically meaningful. In free-running animals, a period difference of $0.2 \mathrm{~h}$ means that a phase difference of $2 \mathrm{~h}$ will be attained in only 10 days (and a phase difference of $12 \mathrm{~h}$ will be attained in two months). In animals entrained to a 24-h environmental cycle, the phase angle of entrainment will be affected, possibly causing a nocturnal animal to venture into the light phase of the light-dark cycle.

The difference in circadian period between mice fed the Western diet and mice fed the control diet was attained by repression of the natural lengthening of the circadian period observed in mice maintained in constant darkness and fed a standard low-fat diet (Davis and Menaker 1981, Possidente et al. 1995, Refinetti 2015). In both experiments, mice fed the Western diet ingested more energy than mice fed the control diet. They did not exercise more than mice fed the control diet and gained more body weight. Although either an increase in exercise or a reduction in energy intake can lead to a reduction in body mass and adiposity (Verheggen et al. 2016), the mice in this study did not increase energy expenditure in response to the increase in energy intake and, consequently, gained weight.

Two previous studies reported a similarly small $(0.2 \mathrm{~h})$ effect of high-fat diets on the circadian period of locomotor activity of mice (Kohsaka et al. 2007; Mendoza et al. 2008), but the reported effect was in the opposite direction (i.e., lengthening rather than shortening of the circadian period). It is possible that mice of the inbred C57BL/6J strain (which were used in those two studies) differ from mice of the outbred CD1 strain (which were used in the present study) in their response to high-fat diet. Different mouse strains have been previously shown to differ in various aspects of the operation of the circadian system (Refinetti 2003; Castillo et al. 2005; Kopp et al. 2006). It is noteworthy that in the study by Mendoza et al. (2008) the mice fed the high-fat diet were less active than the mice fed the control diet. This difference is important because increased activity is known to shorten the circadian period in rodents (Yamada et al. 1988; Edgar et al. 1991; Kuroda et al. 1997; Mrosovsky 1999; Koteka et al. 2003), and reduced activity in the mice fed the high-fat diet might have caused a lengthening of the circadian period that more than compensated for the shortening induced by the high-fat diet. Studies in other mouse strains and other species would help clarify this matter.

A natural inference from the present results concerning the circadian period of mice fed a Western diet or a control diet would be that some property of the Western diet (presumably its high fat content) indirectly affects the circadian pacemaker in the brain and represses the slowing down of the clock. The fact that decimation of the gut microbiota by broad spectrum antibiotic treatment reversed the effect of Western-diet feeding on the free-running circadian period suggests that the effect of Western-diet feeding on the circadian system is mediated by the gastrointestinal microbiota. This finding is particularly relevant in view of the recent discovery about the relationship between gut microbes, circadian clock function, and obesity. Leone and colleagues found that germ-free mice exhibit markedly impaired circadian clock gene expression and, unlike their conventionally raised counterparts, do not gain weight when fed a high-fat diet (Leone et al. 2015). It is meaningful that antibiotic treatment in the present study both nullified the effect of Western-diet feeding on the free-running period and reduced (though not significantly so) the weight gain caused by Western-diet feeding.

The present study has a few limitations that could be avoided in further research. First, decimation of the gut microbiota was not confirmed by examination of fecal samples or intestinal smears. The same antibiotic treatment as that used by Vijay-Kumar et al. (2010), who conducted cecal microbiota quantification, was used in the present study, but the exact extent of microbial decimation achieved in this study cannot be ascertained. Second, Westerndiet feeding elicited not only shortening of the circadian period but also weight gain. Thus, it cannot be determined whether the shortening of the circadian period was caused by dietary fat itself or by the development of obesity. It is unlikely, however, that weight gain would cause a change in circadian period, as obesity has been shown not to affect circadian period in rats (Mistlberger et al. 1998) and mice (Sans-Fuentes et al. 2010). Third, the effects of Western-diet feeding were studied for only two months. It is possible that stronger (or even weaker) effects would have been observed after many additional months. Researchers conducting future studies may wish to plan for longer intervals of data collection to ensure that additional changes do not occur after many months. Finally, although antibiotic treatment seemed to counteract the effect of the high-fat diet in this study, the effects of antibiotic treatment by itself on the mammalian circadian system have not been previously studied and may be 
This is an author-produced, peer-reviewed version of this article. The final, definitive version of this document can be found online at Biological Rhythm Research, published by Taylor \& Francis. Copyright restrictions may apply. doi: 10.1080/09291016.2016.1254873

significant. Further research will help determine the relative roles of high-fat diet and antibiotic treatment on the circadian system. Antibiotic treatment affecting different microbial populations will likely have different effects on the circadian system.

\section{Conflict of Interest}

The author declares that he has no conflict of interest.

\section{Ethical Approval}

All applicable international, national, and institutional guidelines for the care and use of animals were followed. All procedures performed in studies involving animals were in accordance with the ethical standards of the institution at which the studies were conducted.

\section{References}

Abete I, Astrup A, Martínez JA, Thorsdottir I, Zulet MA. 2010. Obesity and the metabolic syndrome: role of different dietary macronutrient distribution patterns and specific nutritional components on weight loss and maintenance. Nutr Rev 68: 214-231.

Albenberg LG, Wu GD. 2014. Diet and the intestinal microbiome: associations, functions, and implications for health and disease. Gastroenterology 146: 1564-1572.

Cameron A. 2010. The metabolic syndrome: validity and utility of clinical definitions for cardiovascular disease and diabetes risk prediction. Maturitas 65: 117-121.

Castillo MR, Hochstetler KJ, Greene DM, Firmin SI, Tavernier RJ, Raap DK, Bult-Ito A. 2005. Circadian rhythm of core body temperature in two laboratory mouse lines. Physiol Behav 86: 538-545.

Conlon MA, Bird AR. 2014. The impact of diet and lifestyle on gut microbiota and human health. Nutrients 7: 1744.

Cordain L, Eaton, SB, Sebastian, A, Mann N, Lindeberg S, Watkins BA, O’Keefe JH, Brand-Miller J. 2005. Origins and evolution of the Western diet: health implications for the 21st century. Am J Clin Nutr 81: 341-354.

Davis FC, Menaker M. 1981. Development of the mouse circadian pacemaker: independence from environmental cycles. J Comp Physiol A 143: 527-539.

Edgar DM, Martin CE, Dement WC. 1991. Activity feedback to the mammalian circadian pacemaker: influence on observed measures of rhythm period length. J Biol Rhythms 6: 185-199.

Gade W, Schmitt J, Collins M, Gade J. 2010. Beyond obesity: the diagnosis and pathophysiology of metabolic syndrome. Clin Lab Sci 23: 51-61.

Hsieh MC, Yang SC, Tseng HL, Hwang LL, Chen CT, Shieh KR. 2010. Abnormal expressions of circadian clock and circadian clock controlled genes in the livers and kidneys of long-term, high-fat-diet-treated mice. Int $\mathrm{J}$ Obes 34: 227-239.

Jaworowska A, Blackham T, Davies IG, Stevenson L. 2013. Nutritional challenges and health implications of takeaway and fast food. Nutr Rev 71: 310-318.

Kirk RE. 1995. Experimental design: procedures for the behavioral sciences, 3rd edn. Brooks/Cole, Pacific Grove.

Kohsaka A, Laposky AD, Ramsey KM, Estrada C, Joshu C, Kobayashi Y, Turek FW, Bass J. 2007. High-fat diet disrupts behavioral and molecular circadian rhythms in mice. Cell Metab 6: 414-421.

Koteja P, Swallow JG, Carter PA, Garland T. 2003. Different effects of intensity and duration of locomotor activity on circadian period. J Biol Rhythms 18: 491-501.

Kopp C, Ressel V, Wigger E, Tobler I. 2006. Influence of estrous cycle and ageing on activity patterns in two inbred mouse strains. Behav Brain Res 167: 165-174.

Kuroda H, Fukushima M, Nakai M, Katayama T, Murakami N. 1997. Daily wheel running activity modifies the period of free-running rhythms in rats via intergeniculate leaflet. Physiol Behav 61: 633-637.

Leone V, Gibbons SM, Martinez K, Hutchison AL, Huang EY, Cham CM, Pierre JF, Heneghan AF, Nadimpalli A, Hubert N, Zale E, Wang Y, Huang Y, Theriault B, Dinner AR, Musch MW, Kudsk KA, Prendergast BJ, Gilbert JA, Chang EB. 2015. Effects of diurnal variation of gut microbes and high-fat feeding on host circadian clock function and metabolism. Cell Host Microbe 17: 681-689.

Mendoza J, Pévet P, Challet E. 2008. High-fat feeding alters the clock synchronization to light. J Physiol 586: 59015910. 
This is an author-produced, peer-reviewed version of this article. The final, definitive version of this document can be found online at Biological Rhythm Research, published by Taylor \& Francis. Copyright restrictions may apply. doi: 10.1080/09291016.2016.1254873

Mistlberger RE, Lukman H, Nadeau BG. 1998. Circadian rhythms in the Zucker obese rat: assessment and intervention. Appetite 30: 255-267.

Mrosovsky N. 1999. Further experiments on the relationship between the period of circadian rhythms and locomotor activity levels in hamsters. Physiol Behav 66: 797-801.

Myles IA. 2014. Fast food fever: reviewing the impacts of the Western diet on immunity. Nutr J 13: art 61.

Nakahata Y, Sahar S, Astarita G, Kaluzova M, Sassone-Corsi P. 2009. Circadian control of the NAD ${ }^{+}$salvage pathway by CLOCK-SIRT1. Science 324: 654-657.

Peek CB, Affinati AH, Ramsey KM, Kuo H, Yu W, Sena LA, Ilkayeva O, Marcheva B, Kobayashi Y, Omura C, Levine DC, Denu JM, Mrksich M, Bass J. 2013. Circadian clock NAD ${ }^{+}$cycle drives mitochondrial oxidative metabolism in mice. Science 342: 591.

Possidente B, Mceldowney S, Pabon A. 1995. Aging lengthens circadian period for wheel-running activity in C57BL mice. Physiol Behav 57: 575-579.

Ramsey KM, Yoshino J, Brace CS, Abrassart D, Kobayashi Y, Marcheva B, Hong HK, Chong JL, Buhr ED, Lee C, Takahashi JS, Imai S, Bass J. 2009. Circadian clock feedback cycle through NAMPT-mediated NAD ${ }^{+}$ biosynthesis. Science 324: 651-654.

Refinetti R. 2003. Effects of prolonged exposure to darkness on circadian photic responsiveness in the mouse. Chronobiol Int 20: 417-440.

Refinetti R. 2004. Non-stationary time series and the robustness of circadian rhythms. J Theor Biol 227: 571-581.

Refinetti R. 2015. Comparison of light, food, and temperature as environmental synchronizers of the circadian rhythm of activity in mice. J Physiol Sci 65: 359-366.

Refinetti R, Menaker M. 1997. Is energy expenditure in the hamster primarily under homeostatic or circadian control? J Physiol 501: 449-453.

Ridaura VK, Faith JJ, Rey FE, Cheng J, Duncan AE, Kau AL, Griffin NW, Lombard V, Henrissat B, Bain JR, Muehlbauer MJ, Ilkayeva O, Semenkovich CF, Funai K, Hayashi DK, Lyle BJ, Martini MC, Ursell LK, Clemente JC, Van Treuren W, Walters WA, Knight R, Newgard CB, Heath AC, Gordon JI. 2013. Gut microbiota from twins discordant for obesity modulate metabolism in mice. Science 341: 1079.

Sans-Fuentes MA, Díez-Noguera A, Cambras T. 2010. Light responses of the circadian system in leptin deficient mice. Physiol Behav 99: 487-494.

Sokolove PG, Bushell WN. 1978. The chi square periodogram: its utility for analysis of circadian rhythms. J Theor Biol 72: 131-160.

Spalding A, Kernan J, Lockette W. 2009. The metabolic syndrome: a modern plague spread by modern technology. J Clin Hypertens 11: 755-760.

Verheggen RJ, Maessen MF, Gree DJ, Hermus AR, Hopman MT, Thijssen DH, 2016. A systematic review and meta-analysis on the effects of exercise training versus hypocaloric diet: distinct effects on body weight and visceral adipose tissue. Obes Rev 17: 664-690.

Vijay-Kumar M, Aitken JD, Carvalho FA, Cullender TC, Mwangi S, Srinivasan S, Sitaraman SV, Knight R, Ley RE, Gewirtz AT. 2010. Metabolic syndrome and altered gut microbiota in mice lacking Toll-like receptor 5. Science 328: 228-231.

Yamada N, Shimoda K, Ohi K, Takahashi S, Takahashi K. 1988. Free-access to a running wheel shortens the period of free-running rhythm in blinded rats. Physiol Behav 42: 87-91. 

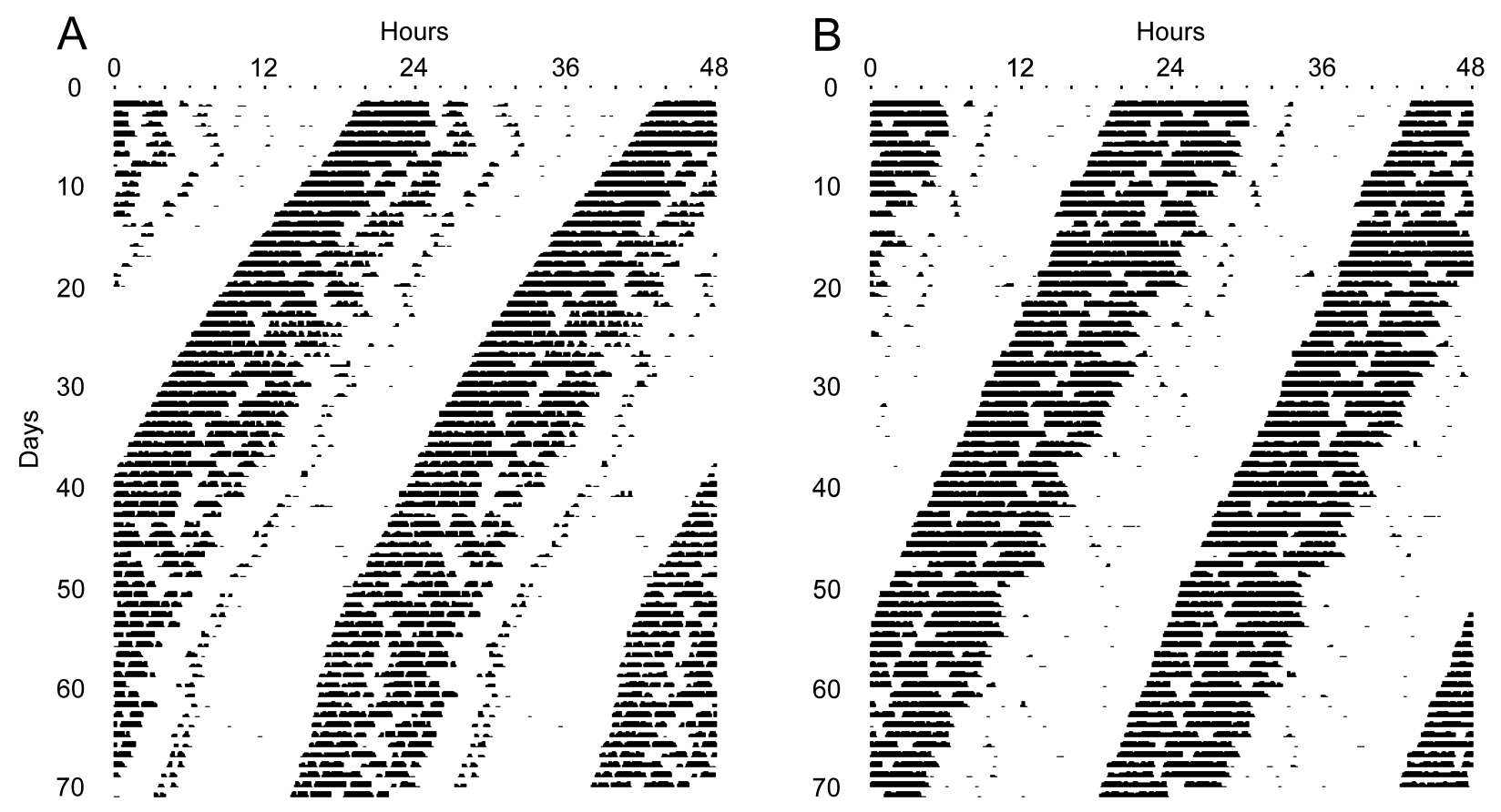

Figure 1. Double-plotted actograms of running-wheel activity of two representative mice housed in constant darkness. Time of day is indicated on the horizontal axis and number of days on the vertical axis. During the first three weeks, both mice were fed standard rodent chow. Starting on Day 22, one mouse was fed a control diet (A) whereas the other was fed a special diet mimicking human Western diet (B).

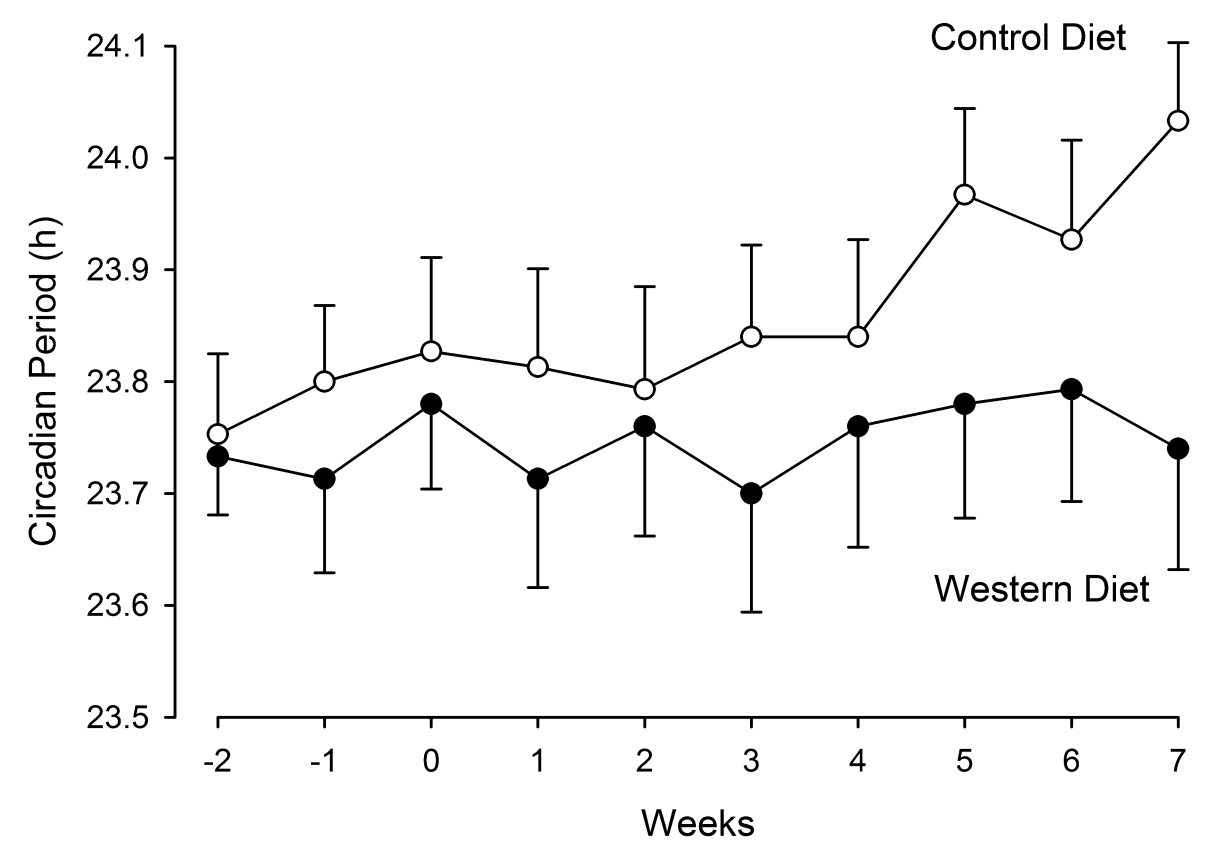

Figure 2. Mean ( \pm SEM) free-running periods of mice housed in constant darkness for 10 weeks. During the first three weeks, both groups of mice were fed standard rodent chow. Afterwards, one group was fed a control diet $(\mathrm{n}=$ $15)$ and the other was fed a Western diet $(n=15)$. 
This is an author-produced, peer-reviewed version of this article. The final, definitive version of this document can be found online at Biological Rhythm Research, published by Taylor \& Francis. Copyright restrictions may apply. doi: 10.1080/09291016.2016.1254873
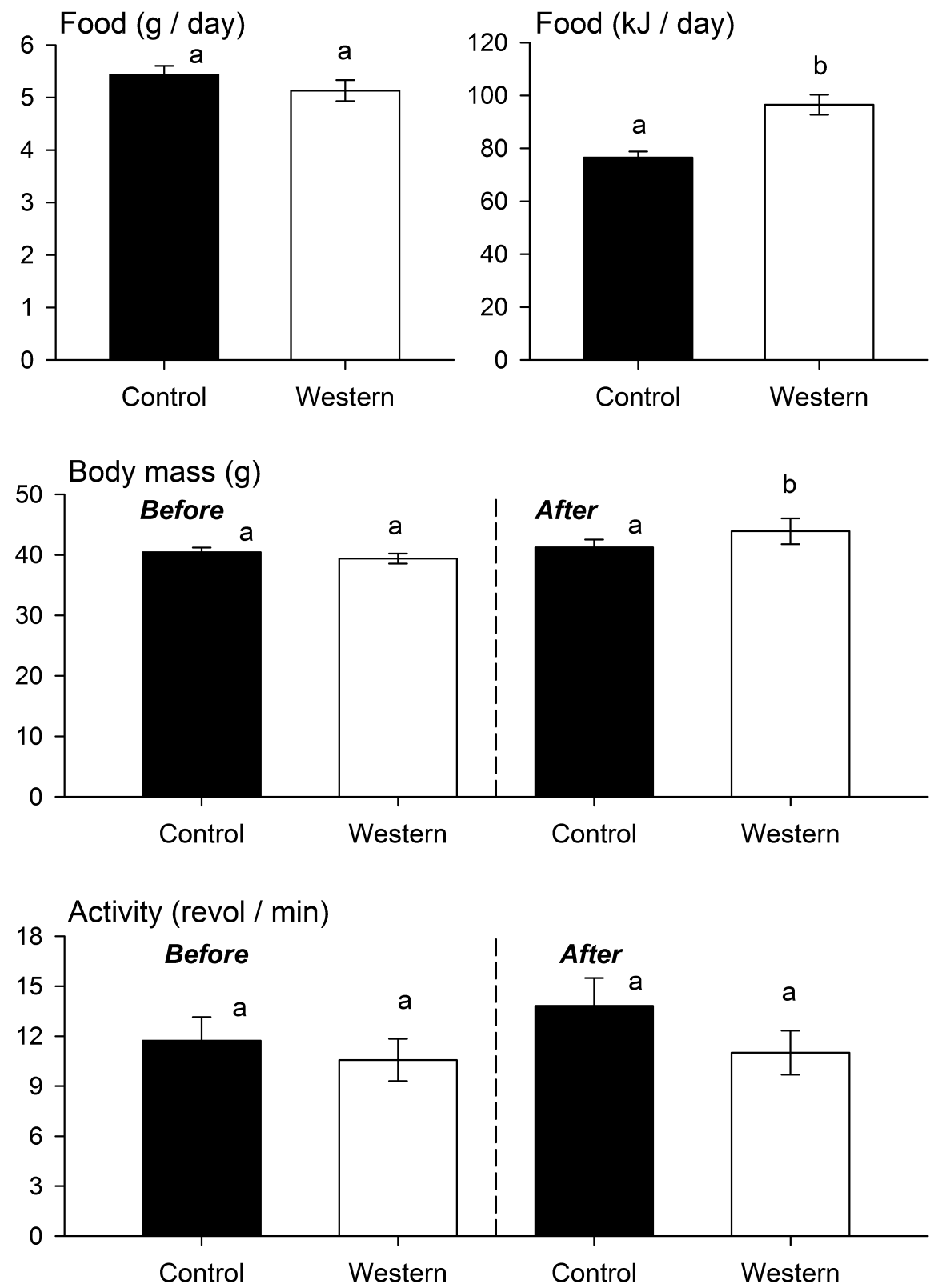

Figure 3. Mean $( \pm$ SEM) values of food intake, body mass, and running-wheel activity of two groups of mice housed in constant darkness and fed either a control diet $(n=15)$ or a Western diet $(n=15)$. In each panel, bars with the same letter (a or b) are not significantly different from each other, as determined by $t$ tests or post hoc comparisons with Tukey's HSD test. 
This is an author-produced, peer-reviewed version of this article. The final, definitive version of this document can be found online at Biological Rhythm Research, published by Taylor \& Francis. Copyright restrictions may apply. doi: 10.1080/09291016.2016.1254873

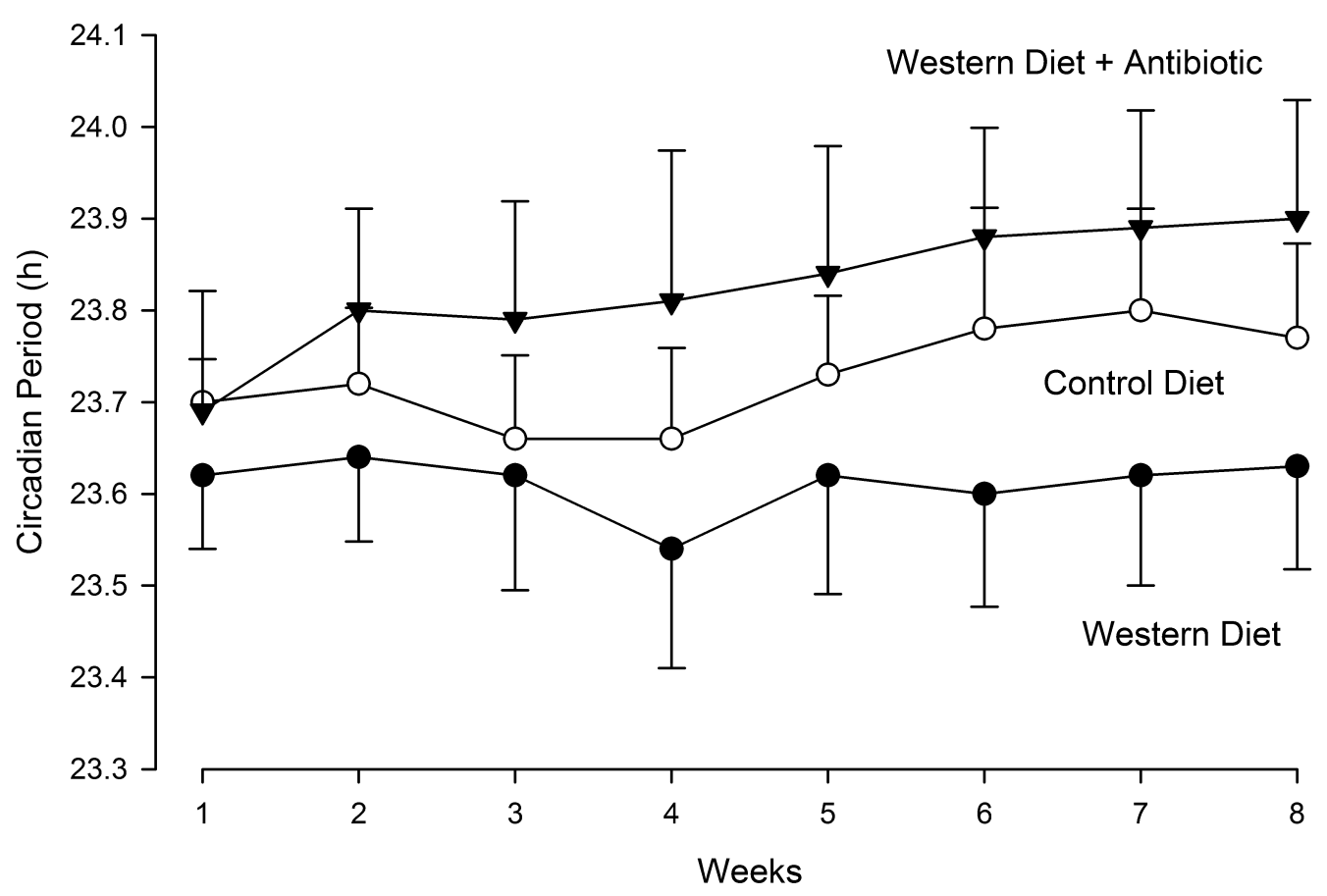

Figure 4. Mean ( \pm SEM) free-running periods of mice housed in constant darkness for 8 weeks while being fed a control diet $(\mathrm{n}=10)$, a Western diet $(\mathrm{n}=10)$, or a Western diet along with antibiotics in the drinking water $(\mathrm{n}=10)$. 
This is an author-produced, peer-reviewed version of this article. The final, definitive version of this document can be found online at Biological Rhythm Research, published by Taylor \& Francis. Copyright restrictions may apply. doi: 10.1080/09291016.2016.1254873
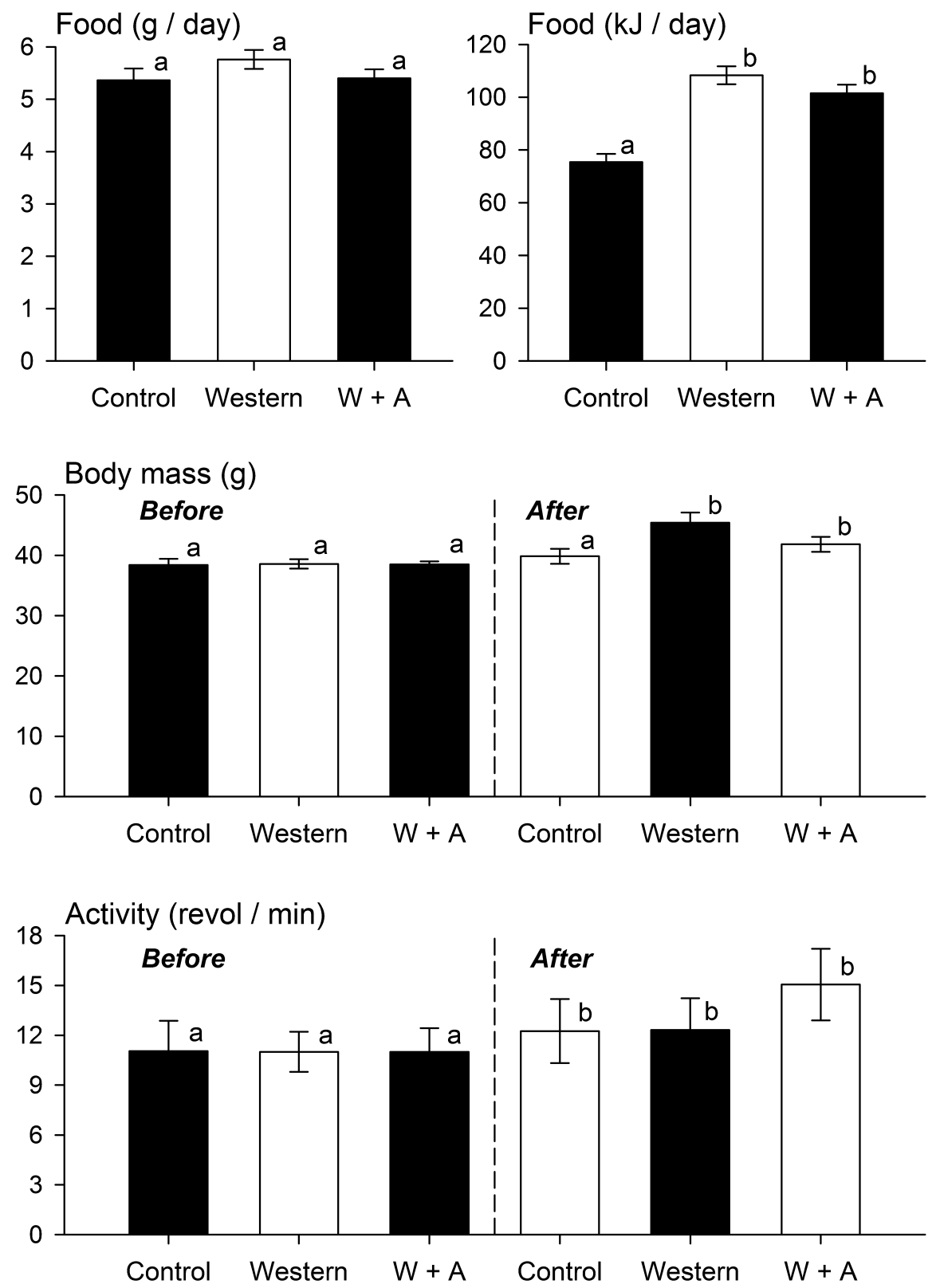

Figure 5. Mean $( \pm$ SEM) values of food intake, body mass, and running-wheel activity of three groups of mice housed in constant darkness and fed a control diet $(n=10)$, a Western diet $(n=10)$, or a Western diet along with antibiotics in the drinking water $(\mathrm{n}=10)$. In each panel, bars with the same letter $(\mathrm{a}$ or $\mathrm{b})$ are not significantly different from each other, as determined by post hoc comparisons with Tukey’s HSD test. 